\title{
Características de las noticias procedentes de los departamentos de comunicación que influyen en el uso y reelaboración por parte de los periodistas
}

\author{
Lorena BuSTO SALINAS \\ Universidad de Burgos \\ lbusto@ubu.es
}

\section{Resumen:}

Se pretende averiguar si algunos aspectos de una nota de prensa, al margen de los elementos puramente noticiosos, influyen en que sea divulgada y de qué manera. Para ello, se analiza el tema, la extensión y los protagonistas de las notas emitidas en cuatro años por la Fundación Atapuerca (Burgos, España) y su repercusión en seis periódicos. Se ha constatado, entre otras cosas, que el tema más exclusivo es el único que tiene mayores posibilidades de publicarse y con una mayor trascendencia. La extensión de la nota o la mención de un personaje relevante no influyen en la decisión del redactor.

Palabras clave: relaciones públicas; comunicación externa; medios de comunicación; nota de prensa; análisis de prensa

\section{Characteristics of the stories sent by communication departments that has influence on journalists' use and modification}

\begin{abstract}
:
The aim of this research is to find out if some aspects of press releases, apart from the newsworthy characteristics, have influence on whether the text is eventually published and in which way. The subject, the extension and the main characters of all press releases sent in four years by Atapuerca Foundation (Burgos, Spain) have been collected, as well as their penetration in six newspapers. It has been proved, among other things, that the most exclusive subject is the only one that has more possibilities to appear in the press and with a better relevance. However, the mention of a famous person or the extension of the press release do not have any influence on journalists.
\end{abstract}

Key Words: public relations; external communication; mass media; press release; press analysis

\section{Referencia normalizada:}

Busto Salinas, L. (2014): Características de las noticias procedentes de los departamentos de comunicación que influyen en el uso y reelaboración por parte de los periodistas . Historia y Comunicación Social. Vol. 19. Núm. Especial Marzo. Págs. 265-276.

Sumario: 1.1. Introducción. 1.1. Influencia del tema. 1.2. Influencia de la extensión 1.3. Influencia de los personajes mencionados. 2. Objetivos. 3. Metodología. 4. Resultados. 4.1. Influencia del tema. 4.1.1. Primera página. 4.1.2. Fotografías. 4.1.3. Extensión de la información. 4.1.4. Información de archivo. 4.1.5. Elaboración propia. 4.2. Influencia de la extensión. 4.3. Influencia de los personajes mencionados.

5. Conclusiones. 6. Referencias bibliográficas. 


\section{Introducción}

Los gabinetes de comunicación son departamentos activos, organizados y habitualmente estables de las empresas e instituciones que controlan, analizan, ejecutan y difunden todas las actividades de comunicación de la entidad (Martín Martín, 1998; Ramírez, 1995a). Su función es tan necesaria en el actual sistema informativo que "si no existieran los gabinetes de prensa, habría que inventarlos" (Ramírez, 1995b). Una de sus principales tareas es proporcionar información puntual sobre una entidad a los medios de comunicación, de tal forma que estos puedan publicar la noticia e influir así en la opinión pública.

Una de las principales y más importantes herramientas en el trabajo diario de un gabinete de comunicación en su relación con los periodistas es la nota de prensa. Se trata de un texto informativo breve enviado a los medios de comunicación sobre un tema de interés periodístico de la entidad que lo emite y que suele escribirse de la misma manera en que lo haría un redactor con el fin de que se publique sin contraprestación económica y con la menor modificación posible. Las organizaciones consiguen de una manera poco costosa sacar a la luz las noticias que desean y los periodistas obtienen ideas con las que poder redactar historias en sus medios sin demasiadas complicaciones.

Esta relación ha incluso originado el debate de "si los gabinetes de las organizaciones están influyendo excesivamente en el contenido de los medios de comunicación" (Castillo Esparcia, 2002: 563-564). Y es que los textos publicados en los periódicos sobre noticias originadas por estos departamentos aumentan año tras año: mientras que en 1978 constituían el 30\% de la información, en 1992 esta cifra sube hasta el $52 \%$. Se cree, además, que este porcentaje ha continuado ascendiendo, de tal forma de que hay quien sugiere que a principios del siglo XXI ha alcanzado el 80\% (Elías, 2003) o incluso el 83\% (Villafañe, Bustamante y Prado, 1987).

\subsection{Influencia del tema}

Con el fin de conocer por qué unas notas de prensa tienen más cabida en los periódicos que otras, varios estudiosos han analizado si el tema principal constituye un elemento influyente. Morton y Ramsey (1994), por ejemplo, descubrieron que únicamente el tema abordado tiene una relación positiva con las posibilidades de publicación, a pesar de que no sucede lo mismo con la fuente emisora, el tipo de comunicado y los elementos noticiosos. Los profesores advirtieron que las finanzas es el grupo que más probabilidades de publicación presenta; de hecho, el $83 \%$ de las notas analizadas provenían de este mundo empresarial. Este tema se encuentra en la posición más alta en tasa de publicación en otra indagación de Walters y Walters (1992), los cuales establecen tres categorías que inciden en la divulgación: economía y finanzas, tiempo libre y turismo, y ciencia. En cuanto a las noticias procedentes de agencias de noticias, el $25,8 \%$ que se publican posteriormente en los periódicos tratan temas científicos; el 18,2\%, salud; el 15,2\%, educación, y el 9,1\%, economía y personal. 
Vinculada con las finanzas se encuentra la economía, el asunto más recurrente en 24 diarios de Iowa (Estados Unidos) provenientes de la agencia de noticias Associated Press. Con un $23 \%$ del total de las informaciones, se halla por delante de los deportes $(20 \%)$, los actos oficiales del gobierno (14\%), la sociedad y la familia (13\%) (Gold y Simmons, 1965). Los diarios más importantes de Ohio (Estados Unidos), en cambio, son más proclives a seleccionar informaciones de política, trabajo y temas nacionales que de accidentes y desastres, delincuencia, temas humanos o internacionales (Whitney y Becker, 1982).

Pese a todo, lo que realmente marca la diferencia entre una nota de prensa y otra en la elección del redactor es si posee información de utilidad para el lector (Morton, 1986; Pasqua, 1973), es decir, si "toca la vida de los lectores" (Pasqua, 1973). Una muestra de la importancia de este aspecto lo proporciona una universidad de Estados Unidos (Morton y Warren, 1992), en cuyo caso el $72 \%$ de las noticias publicadas contienen este aspecto. Se convierte, así, en el tema más recurrente, seguido, aunque de lejos, de los acontecimientos próximos, que acaparan el $28,2 \%$ de los comunicados publicados.

\subsection{Influencia de la extensión}

Las notas de prensa no deben ocupar más de una página (Cárdenas, 2000). Algunos, incluso, especifican que debe contar con una media de 200 palabras en menos de una página a doble espacio (T. N. Walters, Walters y Starr, 1994). Los vocablos se han de seleccionar con cuidado y las frases tienen que aportar la mayor cantidad de información con el mínimo número de palabras (T. N. Walters, Walters y Starr, 1994). A pesar de todo, no existe una norma prefijada; depende, en gran medida, del acontecimiento que se narre (Rojas, 2003), ya que no ha de tratarse de igual manera una promoción, un evento o una entrega de premios que una noticia sobre la reforma en la ley de las pensiones, por poner varios casos.

A pesar de todo, no se ha indagado acerca de cómo influye la extensión de una nota de prensa en la decisión de un periodista de utilizarla en el medio, ni tampoco en su tratamiento.

\subsection{Influencia de los personajes mencionados}

No existen investigaciones que constaten la posible influencia que pueden tener los personajes que se mencionan en una nota de prensa, ni a la hora de que se publique, ni en el tratamiento que le otorga un periodista una vez decide divulgar la noticia. Aún así, dado que según la teoría de las $5 \mathrm{Ws}$ del periodismo siempre se debe responder a la pregunta “¿quién?" en el primer párrafo de una información (Armentia y Caminos, 2009), puede resultar comprensible que un texto que mencione a una persona relevante en el panorama informativo tenga más posibilidades de que un periodista le preste mayor atención. 


\section{Objetivos}

Los principales manuales de relaciones públicas y de comunicación empresarial e institucional coinciden en que una nota de prensa tiene más posibilidades de ser publicada cuantos más elementos noticiosos reúna. Esto es, si tiene tintes de actualidad, de proximidad, de consecuencias, de conflicto, de utilidad, etc. (Muñoz, 1994: 96; Warren, 1951). Sin embargo, no se ha determinado si otras características de la nota de prensa al margen de los elementos noticiosos propiamente dichos tienen alguna influencia en la posterior publicación en los periódicos o en el tratamiento que los periodistas hacen del texto que reciben.

Por ello, se han seleccionado tres particulares de la nota de prensa (el tema, la extensión y los protagonistas mencionados) con el fin de observar si tienen alguna influencia en la decisión del redactor a la hora de publicar la noticia. Asimismo, también se quiere comprobar si ejerce alguna presión sobre otros aspectos importantes de la divulgación, como la extensión del texto, la inclusión de fotografías y el tamaño de estas, la referencia en primera página, el grado de elaboración propia del periodista y la utilización de información de archivo.

\section{Metodología}

Se han recogido todos los comunicados emitidos a los medios de comunicación durante cuatro años (de 2007 a 2010) por parte de la Fundación Atapuerca. Se trata de una entidad nacida en el año 2000 con sede en Ibeas de Juarros (Burgos) que tiene por objetivo difundir, facilitar la continuidad y respaldar organizativa y económicamente el proyecto de investigación de la Sierra de Atapuerca. Esta fundación no inserta publicidad en los medios de comunicación, con lo que se reduce la influencia positiva que puede emanar del pago de ciertos espacios publicitarios (Choi y Park, 2011).

Durante los cuatro años analizados, la entidad ha enviado 164 textos, distribuidos de la siguiente manera: 40 en 2007, 28 en 2008, 48 en 2009 y otros 48 en 2010. Asimismo, se han recogido todas las informaciones procedentes de estos documentos publicadas en seis periódicos de diferentes características. Estos son dos locales-provinciales: Diario de Burgos y El Correo de Burgos; dos regionales: El Norte de Castilla y $A b c$ en su versión de Castilla y León; y dos nacionales: El País y La Vanguardia. Todas las referencias han sido catalogadas e introducidas en una base de datos.

Finalmente, se ha procedido a relacionar las diferentes características de las notas de prensa con las apariciones en los periódicos con el programa estadístico Statistical Package for the Social Sciences (SPSS). El nivel de significación se ha establecido en igual o menor de 0,005 , de tal forma que las relaciones sean claramente significativas y no valga cualquier pequeña diferencia entre lo esperado y lo encontrado. 


\section{Resultados}

Las notas de prensa de la Fundación Atapuerca gozan de una gran relevancia en los periódicos analizados. De las 164 enviadas en cuatro años, los periódicos han utilizado un total de 115 (el 70,1\%). Es decir, 7 de cada 10 comunicados emitidos por esta institución al tenido, al menos, una aparición en un periódico. Se trata de un porcentaje mucho más alto de lo que proporcionan otras investigaciones, cuya cifra más alta se queda en el 59,2\% (Martin y Singletary, 1981). Además, como algunas notas han sido publicadas por más de un diario a la vez, el número total de textos periodísticos procedente de estos documentos asciende a 240 . Se puede concretar, entonces, que por cada nota de prensa enviada, se han publicado de media 1,46 informaciones en los periódicos, o lo que es lo mismo, por cada 2 emitidas, se han divulgado 3 textos.

Como era de esperar, no todos los diarios han hecho uso del mismo número de notas. Existen tres grupos claramente diferenciados: los locales, los regionales y los nacionales. Los primeros reúnen el 78\% de todas las informaciones (es decir, 187 textos), por delante de los regionales, que cuentan con el $20 \%$ de las apariciones o con 48 publicaciones. Los nacionales, con 5 textos, arrojan una cifra mínima: el $2,1 \%$. No existen diferencias llamativas entre los dos periódicos analizados dentro de cada categoría geográfica.

\subsection{Influencia del tema}

Se han dividido las notas de prensa según los siguientes temas: comunicados institucionales, acuerdos de colaboración, acciones de divulgación, investigación, yacimientos, premios y otros. Debido al alto número de documentos englobados dentro de divulgación, se ha dividido este asunto en: exposiciones, publicaciones, congresos, ferias y otros. Los resultados no muestran una relación significativa entre el tema de un comunicado y las posibilidades de publicación considerando el conjunto de periódicos analizados en esta investigación como una única variable. Es decir, no existe un asunto que interese más que otros y de igual manera a diarios de diferentes características.

No obstante, la situación cambia si se analizan los periódicos por separado o se agrupan según su ámbito geográfico. En este caso, sí que existe una relación entre las notas que versan sobre investigación y los periódicos regionales y nacionales. Seis de los ocho comunicados que trataban este asunto fueron publicados por los diarios regionales (75\%); cuando se trata de otra temática, el nivel de penetración en este grupo cae hasta el $18,6 \%$. Con los periódicos nacionales ocurre algo muy similar. Las cinco informaciones que publicaron El País y La Vanguardia en los cuatro años analizados provienen exclusivamente de documentos de esta temática; del resto, no hicieron uso de ninguno.

En el lado contrario se encuentra el tema de la divulgación, que en vez de publicarse más a menudo que el resto, se publica en muchas menos ocasiones. Los diarios 
que han obtenido diferencias significativas en este caso son los dos locales y un regional: El Norte de Castilla.

\subsubsection{Primera página}

Solamente se ha detectado un asunto que guarde una relación significativa con la aparición en primera página de los diarios. Se trata de la divulgación, aunque esto no significa que haya más portadas que versan sobre este asunto, más bien al contrario. De las 42 informaciones publicadas sobre esta temática, únicamente 5 (el 11,90\%) tuvieron una mención en primera página. En el resto de temas, el porcentaje sube hasta el 46,58\%. Los diarios locales, por su parte, arrojan el mismo resultado.

\subsubsection{Fotografias}

El asunto de una nota de prensa tiene un influjo en la posterior inclusión de fotografías en los periódicos. Por ejemplo, los textos que tratan sobre divulgación obtienen menos imágenes que los otros temas: el 38\% de estas informaciones se publican con una fotografía, cuando en el resto la inclusión sube hasta el 63,4\%. Las notas que tratan sobre congresos (un subtema dentro de divulgación) también obtienen menos imágenes; solo el 20\% son divulgadas con imágenes, cuando en el resto de casos aumenta hasta el $56,9 \%$.

Dividiendo los periódicos por ámbito geográfico, se aprecia otra relación, en este caso entre las notas de prensa que tratan sobre investigación y los diarios regionales y nacionales. En los primeros, a pesar de que solo publican una imagen junto al texto en el $12,2 \%$ de los casos, cuando se habla de temas de investigación, la cifra sube hasta el 75\%. Los nacionales incluyen fotografías en el 60\% de los textos publicados sobre investigación, el único tema del que se hacen eco.

Calculando la relación entre el tema de la nota de prensa y su posterior inclusión de una fotografía por periódicos por separado, únicamente se ha encontrado una relación significativa: El Correo de Burgos con las notas sobre congresos. Cuando estos dos factores coinciden, el nivel de inserción de una imagen baja al 16,7\%, cuando este diario incluye imágenes en el $81,6 \%$ de los casos.

Asimismo, se ha estudiado si el tema de la nota de prensa influye en el tamaño de las fotografías que publica la prensa, pero solamente se ha encontrado un tema que guarde relación: la investigación. Con este asunto, la extensión media de las imágenes en todos los diarios se sitúa en 53,71 módulos (más de una cara, ya que muchas de estas informaciones ocupan más de una página), cuando en el resto de los casos baja hasta $\operatorname{los} 18,14^{1}$.

\subsubsection{Extensión de la información}

Se han analizado los periódicos en conjunto y divididos por ámbito geográfico para determinar si existe algún tema que suela propiciar un mayor tamaño en prensa. Sin embargo, no se han hallado diferencias significativas. Estudiando los periódicos por 
separado, no obstante, se ha encontrado una correspondencia: se trata de El Norte de Castilla con las comunicaciones institucionales. En este caso, la media de módulos en las informaciones provenientes de notas de prensa institucionales se sitúa en 2,75, mientras que en el resto de textos sube hasta el 24,63. Esto quiere decir que este periódico dedica mucho menos espacio a las noticias institucionales que al resto. No obstante, dado que solo existen diferencias significativas entre un periódico de los seis analizados y un tema en particular, se puede establecer que no hay, a grandes rasgos, ningún asunto en las notas de prensa que incida en la extensión de la información en prensa.

\subsubsection{Información de archivo}

El fondo de la nota de prensa también interviene en la inclusión o no, por parte del periodista, de información de archivo. Uniendo los textos de todos los periódicos donde aparecen datos de archivo frente a los que no, se ha encontrado un tema que despunta sobre el resto: la investigación. En todas las noticias publicadas sobre este asunto se ha incluido información de archivo, cuando en el resto de casos la cifra baja hasta el 29,63\%.

Separando los periódicos por su ámbito de difusión, se puede observar que son los locales los que influyen en que la investigación presente diferencias significativas en el conjunto total. Se puede determinar que existe un nexo entre el tema investigación y la posterior inclusión de datos de archivo en los locales. Esto sucede en el 100\% de la muestra; en el resto de casos, la inserción de información de archivo se sitúa en el $28,7 \%$.

En el otro lado de la balanza se encuentra la divulgación con los periódicos locales: cuando los periodistas se enfrentan a este tipo de asunto en los textos, rara vez utilizan información de archivo. En esta investigación, solo el 16,67\% de las publicaciones procedentes de notas sobre divulgación contienen estos datos, mientras que en otros temas, la inclusión sube al 42,47\%.

\subsubsection{Elaboración propia}

No existe una relación significativa entre la elaboración propia de los periodistas y el tema de la nota de prensa. Sin embargo, sí que se ha encontrado en un subtema de divulgación, más concretamente en el de publicaciones. La media de elaboración propia en este caso sube hasta el $89,07 \%$, cuando en el resto de los casos es bastante más baja: el $54,11 \%$.

Se ha realizado la misma prueba separando los periódicos según el ámbito geográfico y se ha comprobado que son los diarios locales los que hacen que el subtema publicaciones muestre una diferencia significativa en el conjunto de todos los diarios. En estos diarios y con ese tema, la media de elaboración propia del periodista se asemeja al de la media de todos los periódicos en conjunto: $86,50 \%$ frente al $54,95 \%$ del resto de noticias. 
Si se separan los periódicos uno a uno y se halla la relación entre el tema y la elaboración propia, se atisban tres diarios que introducen más elaboración propia en tres asuntos. Se trata de los acuerdos de colaboración en Abc, Diario de Burgos con los premios y El Correo de Burgos con las publicaciones (un subtema de divulgación). A pesar de todo, como se trata de casos aislados que no engloban más a un periódico por separado con un tema diferente cada vez, no se puede extrapolar al objeto de estudio en general.

\subsection{Influencia de la extensión}

Se podría llegar a pensar que un miembro de un gabinete de comunicación compone las noticias importantes de una manera más extensa y las menos relevantes de forma más reducida. Por lo tanto, bajo esta hipótesis, un comunicado largo podría tener más posibilidades de publicarse que uno corto. Sin embargo, no se ha encontrado esta relación en las notas de la Fundación Atapuerca, por lo que se puede concluir que, al menos en para esta entidad, la extensión de una nota de prensa -por exceso o por defecto- no influye necesariamente en la posterior publicación de la noticia.

Sin embargo, podría darse el caso de que el periodista, después de decidirse a publicar una noticia, alargue el texto final en relación con la extensión del documento original. No obstante, tampoco no se ha hallado una correlación significativa, ni calculando los periódicos por separado ni agrupándolos por ámbito geográfico ni en conjunto. Esto implica que la extensión de la nota de prensa no tiene ninguna influencia en el posterior tamaño de la noticia en el periódico.

Tampoco puede concretarse, en base a los resultados de esta investigación, que los redactores tengan que echar mano de archivo o introducir más frases de elaboración propia para alargar o contextualizar una nota de prensa corta. Únicamente un periódico de los seis analizados ha proporcionado diferencias significativas. Se trata Diario de Burgos, cuyos periodistas añaden más líneas propias cuando los comunicados con más cortos. Al haberse encontrado dicha relación con un solo periódico, no puede considerarse una relación globalmente significativa.

La extensión tampoco obtiene ningún peso sobre la aparición de la nota de prensa en la portada de los diarios, por lo que se puede determinar que no existe ninguna relación entre la extensión de los comunicados y la aparición en primera página de un periódico.

\subsection{Influencia de los personajes mencionados}

Se han anotado todas las personas que aparecen en las notas de prensa de la Fundación Atapuerca para comprobar si la alusión de algún personaje influye en la posterior publicación o tratamiento de la información. Así, se ha localizado a los tres codirectores (José María Bermúdez de Castro, Eudald Carbonell y Juan Luis Arsuaga) y al considerado "padre" de los yacimientos (Emiliano Aguirre), que son las figuras más populares del sistema Atapuerca. El resto de personas, debido a la variedad y al alto 
número de apariciones, se han englobado en: protagonistas institucionales, científicos, culturales, empresariales y otros miembros de la Fundación.

Según los resultados de esta investigación, la aparición de al menos una persona en las notas de prensa no asegura que el texto se vaya a publicar ni tiene un dominio sobre el tamaño de la información en el periódico. Separando las referencias según personas o grupos, no obstante, se hallan varias coincidencias. Por ejemplo, existen más probabilidades de que los diarios regionales divulguen una noticia en la que se nombra a alguna persona del ámbito institucional: el 45,8\% de los comunicados con esta referencia son elegidos en comparación con el $17,1 \%$ de los que son publicados cuando no se proporciona esta mención. Ocurre justamente lo contrario con los periódicos locales y los protagonistas científicos. Cuando en una nota de prensa se menciona a este tipo de personas, las probabilidades de publicación bajan del 75,19\% al $48,39 \%$.

También se ha encontrado que las posibilidades de publicación aumentan cuando se unen varios personajes relevantes de una misma organización, tal y como sucede en la Fundación Atapuerca con los tres codirectores. Todas las notas de prensa (18) en las que se nombraban a estos científicos tuvieron al menos una repercusión en prensa (lo que proporciona un nivel de penetración del 100\%), mientras que cuando no se hace alusión en conjunto a estas tres personas, el porcentaje baja al 66,44\%.

Visto que existen más posibilidades de que una nota sea difundida por los medios cuando se mencionan a los tres codirectores, se ha querido comprobar si estas referencias influyen también en el tamaño del texto final. Efectivamente, los periódicos regionales divulgan una información más amplia cuando esto sucede. Concretamente, revelan una media de 35,21 módulos frente a los 15,11 módulos de las noticias en las que no aparecen los tres codirectores.

Se ha analizado si existe alguna relación entre la inclusión en la nota de prensa de algún personaje y su posterior publicación en portada. A pesar de haber examinado los periódicos según ámbitos, como un conjunto y por sí mismos, no se han hallado diferencias significativas. Tampoco se ha encontrado ninguna relación entre ningún personaje y la colocación de una fotografía junto al texto periodístico. Por todo ello, se puede establecer que no hay una dependencia entre la mención de protagonistas en un comunicado y su posterior inserción en primera página de un periódico o el uso de imágenes para ilustrar el contenido.

\section{Conclusiones}

La nota de prensa continúa siendo una herramienta eficaz para informar a los medios de comunicación acerca de las actividades o posturas que adopta una entidad. Una muestra de ello lo proporciona la Fundación Atapuerca: el 70,1\% de todos los textos enviados a los medios durante cuatro años tuvieron, al menos, una repercusión en prensa. 
No obstante, no todos esos documentos fueron divulgados de la misma manera. Por ejemplo, los temas sobre los yacimientos o la investigación fueron los que más se publicaron. Además, estos asuntos suelen ocupar más espacio en los periódicos, poseen más fotografías y más grandes y figuran en mayor medida en portada. En el lado contrario se encuentran los temas que suelen abordar casi todos los gabinetes de comunicación, es decir, los comunicados institucionales, los acuerdos de colaboración y las actividades de divulgación. En estos casos, la extensión es más corta y raramente aparecen en primera página.

Esto implica que el tema que mayor repercusión en prensa obtiene es aquel que se distancia de lo que otras fuentes informativas ofrecen y que se muestra como una información exclusiva que no puede adquirirse por otros procedimientos. Además de su publicación, también influye en la importancia que le otorga el medio a las noticias, ya que suelen ocupar más espacio, aparecen acompañadas de fotografías y figuran en portada más veces que el resto.

La extensión de una nota de prensa -por exceso o por defecto- no influye en la posterior publicación de la noticia ni en el tratamiento que realiza el redactor de ella. La mención de un personaje importante tampoco contribuye a que una noticia se divulgue, salvo si se unen las personas más relevantes de la entidad. En este caso, las opciones de publicación aumentan, así como el espacio que le otorga el periodista a la noticia.

\section{Bibliografía}

ARMENTIA, J. I. y CAMINOS, J. M. (2009). Redacción informativa en prensa. Barcelona: Ariel.

CÁRDENAS, M. L. (2000). Gabinetes de prensa municipales en la provincia de Sevilla: la información como servicio local. Sevilla: Diputación de Sevilla.

CASTILLO ESPARCIA, A. (2002). "El papel de las fuentes. Relaciones entre gabinetes de comunicación y medios de comunicación". En VV.AA. (ed.). Prensa y periodismo especializado. Guadalajara: Ayuntamiento de Guadalajara. Pp. 563-572.

CHOI, J. y PARK, S. (2011). "Influence of advertising on acceptance of press releases". En: Public Relations Review, $\mathrm{n}^{\circ} 37$.

ELÍAS, C. (2003). "Adaptación de la metodología de "observación participante" al estudio de los gabinetes de prensa como fuentes periodísticas". En: Empiria: Revista de metodología de ciencias sociales, $\mathrm{n}^{\circ} 6$, pp. 145-162.

EL PAÍS (2010). Publicidad El País. En: http://www.elpais.com/corporativos/elpais/ publi.html?valor=3\&subvalor $=1$. [08-02-2011].

GOLD, D. y SIMMONS, J. L. (1965). "News Selection Pattern Among Iowa Dailies". En: Public Opinion Quarterly, no 29, pp. 425-430.

MARTIN, W. P. y SINGLETARY, M. W. (1981): "Newspaper treatment of state government releases". En: Journalism Quarterly, nº 58, pp. 93-96. 
MARTÍN MARTÍN, F. (1998). Comunicación empresarial e institucional. Madrid: Universitas.

MORTON, L. P. (1986). "How newspapers choose the releases they use". En: Public Relations Review, $\mathrm{n}^{\circ} 12$, vol. 3, pp. 22-27.

MORTON, L. P. y RAMSEY, S. (1994). "A benchmark study of the PR news wire". En: Public Relations Review, no 20, vol. 2, pp. 171-182.

MORTON, L. P. y WARREN, J. (1992). "News elements and editors' choices". En: Public Relations Review, $\mathrm{n}^{\mathrm{o}}$ 18, pp. 47-52.

MUÑOZ, J. J. (1994). Redacción periodística: teoría y práctica. $2^{\mathrm{a}}$ ed. Salamanca: Librería Cervantes.

PASQUA, T. M. J. (1973). A Readership Model of News Value. Austin (Texas): University of Texas at Austin.

RAMÍREZ, T. (1995a). Gabinetes de comunicación: funciones, disfunciones e incidencia. Barcelona: Bosch.

(1995b). "La influencia de los gabinetes de prensa. Las rutinas periodísticas al servicio del poder". En: Telos, n ${ }^{\circ} 40$, pp. 47-57.

ROJAS, O. (2003). "La Nota de Prensa". En: Razón y palabra, no 32.

VILLAFAÑE, J., BUSTAMANTE, E. y PRADO, E. (1987). Fabricar noticias: las rutinas productivas en radio y televisión. Barcelona: Mitre, D.L.

WALTERS, L. M. y WALTERS, T. N. (1992). "Environment of confidence: Daily newspaper use of press releases". En: Public Relations Review, $\mathrm{n}^{\circ}$ 18, pp. 31-46.

WALTERS, T. N., WALTERS, L. M. y STARR, D. P. (1994). "After the highwayman: Syntax and successful placement of press releases in newspapers". En: Public Relations Review, $\mathrm{n}^{\circ}$ 20, vol. 4, pp. 345-356.

WARREN, C. N. (1951). Modern News Reporting. New York: Harper.

WHITNEY, C. D. y BECKER, L. B. (1982). ““Keeping the Gates” for Gatekeepers: The Effects of Wire News". En: Journalism Quarterly, no 59, pp. 60-65.

\section{Notas}

1 Para hacer el análisis de estas divisiones se ha seguido la medición de la publicidad en El País, el diario de información general con mayor tirada en España, que concibe 40 módulos en cada página: 8 por columna y 5 columnas. Las medidas se corresponden con 40 milímetros de alto por 46 de ancho (28) (El País, 2010).

\section{La autora}

Lorena Busto Salinas es licenciada en Comunicación Audiovisual con premio extraordinario al mejor expediente por la Universidad de Burgos, lugar donde ha obtenido el Diploma de Estudios Avanzados con un trabajo sobre comunicación institucional y muy en especial en torno a la nota de prensa. Ha presentado diversas 
ponencias en congresos nacionales e internacionales y ha publicado sendas investigaciones en revistas científicas de impacto. Candidata a doctora, forma parte del grupo de investigación Comunicación, Difusión y Publicidad de la Cultura y del Patrimonio de la Universidad de Burgos (CAYPAT), con el que ha participado y divulgado varias investigaciones sobre la divulgación del patrimonio y la cultura. 